\title{
TAREKAT NAQSYABANDIYAH SYAIKH ABDUL WAHAB ROKAN: Sejarah, Ajaran, Amalan, dan Dinamika Perubahan
}

\author{
L. Hidayat Siregar \\ Fakultas Tarbiyah IAIN Sumatera Utara \\ Jl. Willem Iskandar Pasar V Medan Estate, 20371 \\ e-mail: lindunghidayatsiregar@yahoo.com
}

\begin{abstract}
Tarekat Naqsyabandiyah Syaikh Abdul Wahab Rokan: history, teachings, practice and its dynamics of change. The Tarekat Naqsyabandiyah in North Sumatra was first developed by Syaikh Abdul Wahab Rokan. In reality, such teaching of tarekat developed by him has changed the lives of its followers in Babussalam socially to a more prosperous course. In this article, the writer traces the history, teaching and practice of tarekat Naqsyabandiyah Syaikh Abdul Wahab Rokan in Babussalam as well as analyzes the dynamics of change there in. The author argues that the application of the teaching of tarekat Naqsyabandiyah Syaikh Abdul Wahab Rokan which emphasizes that the material world is not the only matter in life has become an avenue for creating a balance between the profane and eternal dimensions of life.
\end{abstract}

Kata Kunci: Tarekat, Naqsyabandiyah, Syaikh Abdul Wahab Rokan

\section{Pendahuluan}

Naqsyabandiyah adalah sebuah tarekat yang berkembang pesat di Indonesia termasuk di Sumatera Utara. Tidak diketahui secara pasti kapan tarekat ini masuk ke daerah Sumatera Utara, namun jika dikaitkan dengan kompleks pasantren kaum sufi persulukan Babussalam, masyarakat Sumatera Utara lebih sering menyebutnya Basilam, tarekat Naqsyabandiyah memasuki daerah ini menjelang pertengahan abad ke-13 H/19 M. Hal ini dikaitkan dengan berdirinya suluk ${ }^{1}$ di Babussalam, Langkat, Sumatera Utara,

${ }^{1}$ Secara praktis tarekat ini disebut juga dengan suluk atau persulukan Basilam. Kata suluk berasal dari bahasa Arab (sulûk) artinya menempuh jalan. Orang yang menempuh jalan itu disebut sâlik. Maksudnya ialah orang yang berjalan menuju kedekatan dengan Allah SWT. dengan menjalankan ibadah sepanjang malam. Lihat Abdul al-Razzaq al-Kasyani, Istilâhat al-Sufiyah (Kairo : Dâr al-Ma'ârif, 1984), h. 115. Dikalangan tarekat kata suluk mengandung arti latihan 
atas kerjasama Sultan Musa, dari Kesultanan Langkat dengan Syaikh Abdul Wahab Rokan (1811 M-1926 M) sebagai pemimpin (Syaikh) persulukan tersebut. ${ }^{2}$

Munculnya tarekat Naqsyabandiyah di Basilam dibawa oleh Syaikh Abdul Wahab yang berasal dari Rokan, Riau. Untuk mengembangkan ajaran tarekat Naqsyabandiyah, Syaikh Abdul Wahab memulainya di Rokan hingga ke sepanjang pesisir pantai Timur SumateraSiak, Tembusai di Riau sampai ke Kerajaan Kota Pinang, Bilah Panai, Asahan, Kualuh, Deli Serdang hingga ke Basilam di Langkat-. Di Besilam Syaikh Abdul Wahab membangun desa dan madrasah Babussalam guna pengembangan ajaran tarekat, walaupun sempat meninggalkan Babussalam karena dituduh melakukan pemalsuan uang oleh penguasa Belanda pada masa itu, ia akhirnya kembali lagi ke Babussalam melalui undangan Sultan Langkat.

Kampung Basilam dihuni oleh penduduk yang heterogen, terdiri dari berbagai macam suku, seperti Melayu, Mandailing dan Jawa. Agar masyarakat hidup tentram dan damai dibuat suatu peraturan yang disebut Peraturan-peraturan Babussalam. Berdasarkan silsilah ${ }^{4}$ tarekat Naqsyabandiyah ini menduduki urutan ke-17 dari pendiri tarekat tersebut yakni Baha' al-Dîn al-Naqsyabandiyah, dan urutan yang ke-34 dari Nabi Muhammad SAW. ${ }^{5}$

Pokok Ajaran Syaikh Abdul Wahab Rokan adalah keseimbangan kehidupan dunia dan akhirat. Kegiatan yang dilakukan Syaikh Abdul Wahab Rokan dan pengikut tarekatnya tidak hanya berzikir dan bersuluk. Syaikh Abdul Wahab Rokan juga membuka perkebunan karet, jeruk manis dan lada hitam, mengembangkan peternakan dan perikanan serta mendirikan percetakan ${ }^{6}$.

Syaikh Abdul Wahab Rokan juga melibatkan diri dalam urusan politik. Beliau

yang dilakukan dalam jangka waktu tertentu untuk memperoleh keadaan dan maqâm dengan jalan memperbanyak ibadah, intropeksi diri dan berusaha memperbaiki jiwa agar dekat dengan Tuhan. Lihat Syekh al-Kamasykhawani, Jami' al-Usûl fí al-Awtiyâ' (Kairo: Dâr al-Kutub al-Arabiah, t.t.), h. 22. Lihat juga Abu Bakar Aceh, Pengantar Ilmu Tarekat (Semarang: Ramadhani, 1992), h. 121.

${ }^{2}$ H.A. Fuad Said, Syekh Abdul Wahab Tuan Guru Babussalam, cet. 8 (Medan: Pustaka Babussalam, 1998), h. 63-64. Mengenal keberadaan kerajaan Melayu di Langkat dapat dilihat pada T. Luckman Sinar, Kerajaan-Kerajaan Melayu di Sumatera Timur (Medan : Dirasat al-Ulya, 1988).

${ }^{4}$ Silsilah dalam tarekat adalah geneologi otorita spiritual. Silsilah menjelaskan jalur penerimaan tarekat oleh seseorang. Dengan demikian silsilah berfungsi sebagai identitas keotentikan ajaran, sekaligus sebagai sumber otoritas seseorang dalam tarekat. Fazlur Rahman melihat kemungkinan bahwa silsilah ini adalah adaptasi para sufi awal dari lembaga isnâd yang dikembangkan para ahli hadis untuk menjamin otoritas hadis yang mereka riwayatkan. Pada abad ke-4 H/ $10 \mathrm{M}$ sufi al-Khuldi (w. 348 H/959 M) menelusuri garis asal usul ajaran mistiknya sampai kepada Hasan alBasri (w. 110 H/ 728 M) dan dari sini, melalui sahabat Anas ibn Malik, sampai kepada Nabi Muhammad SAW. Lihat Fazlur Rahman, Islam, terj. Ahsan Muhammad (Bandung: Penerbit Pustaka, 1984), h. 226.

${ }^{5}$ Fuad Said, Syekh Abdul Wahab, h. 129.

${ }^{6}$ Percetakan ini adalah yang pertama dalam tulisan Arab di Sumatera Utara. Ibid, h. 118. 
mempunyai hubungan dengan tokoh-tokoh pergerakan Islam, seperti HOS Cokroaminoto dan Raden Gunawan, yang mendirikan Syarikat Islam (SI) pada tahun 1912 kemudian menjadi Partai Syarikat Islam Indonesia (PSII). ${ }^{7}$ Pada tahun 1913 ia mengutus dua orang puteranya ke musyawarah SI di Jawa dan kemudian mendirikan Syarikat Islam cabang Babussalam di mana Syaikh Abdul Wahab Rokan menjadi salah seorang pengurusnya.

Keraguan sebahagian kalangan terhadap tarekat di satu sisi, dan keberhasilan tarekat Naqsyabandiyah dalam membangun tatanan kehidupan sosial pengikutnya di sisi yang lain, menawarkan satu bidang pembahasan yang sangat menarik dan membutuhkan satu eksposisi tersendiri. Kebutuhan inilah yang akan dijawab tulisan ini, meliputi tokoh tarekat Naqsyabandiyah Sumatera Utara, Syaikh Abdul Wahab Rokan, sejarah perkembangannya, pemikiran, amalan, dan perubahan yang dilakukannya.

\section{Biografi Syaikh Abdul Wahab Rokan}

Tidak diketahui secara pasti tanggal kelahirannya, karena terdapat dua pendapat mengenai kelahiran tersebut. Ada yang mengatakan, ia lahir 19 Rabi'ul Akhir $1230 \mathrm{H} /$ 28 September 1811 M. Pendapat lainnya ialah 10 Rabi'ul Akhir 1246 H/28 September 1830 M. ${ }^{8}$ Dari dua pendapat yang ada, pendapat pertama lebih mendekati kebenaran, karena disesuaikan dengan usianya yang diperkirakan sekitar 115 tahun. Namun tanggal wafatnya tidak diperselisihkan, yaitu 21 Jumadil Awal 1345 H atau 27 September 1926 M. Begitu juga tempat kelahirannya tidak diperselisihkan, yaitu di Kampung Danau Rinda, Rantau Binuang Sakti, Negeri Tinggi, Rokan Tengah, Kabupaten Kampar, Propinsi Riau.

Nama kecilnya ialah Abu Qasim. Orang tuanya bernama Abdul Manap bin Muhammad Yasin bin Maulana Tuanku Haji Abdullah Tembusai. Nama terakhir, yang dikenal dengan Haji Abdullah Tembusai, merupakan seorang ulama terkenal di daerah Riau yang mempunyai banyak murid yang tersebar di berbagai daerah, termasuk di daerah Tapanuli. Haji Abdullah Tembusai kawin dengan salah seorang Putri Yang Dipertuan Kota Pinang, sekarang masuk wilayah Kabupaten Labuhan Batu Sumatera Utara. Dari perkawinan ini lahirlah Muhammad Yasin yang turut pindah dari Tembusai bersama ayahnya ke Tanah Putih. Di Tanah Putih Muhammad Yasin menikah dengan gadis setempat bernama Intan dari Suku Batu Hampar, dan dari hasil perkawinan tersebut lahirlah Abdul Manap. Abdul Manap menikah dengan wanita bernama Arba'iyah asal Tanah Putih, putri dari Datuk Bedagai, dan dari pernikahan tersebut lahirlah Abu Qasim, digelar Fakih Muhammad yang kemudian terkenal dengan Syaikh Abdul Wahab Rokan al-Khalidi al-Naqsyabandi, Tuan Guru Babussalam (Basilam). ${ }^{9}$

${ }^{7}$ Fuad Said, Syekh Abdul Wahab, h. 14.

${ }^{8}$ H.A. Fuad Said. Hakikat Tarekat Naqsyabandiyah (Jakarta : PT. al-Husna Zikra, 1999), h. $15-16$.

${ }^{9}$ Ibid., h. 17-19 


\section{Pendidikan dan Perjalanan Hidup}

Seperti kebanyakan anak-anak semasanya, pendidikan awal Abu Qasim dimulai dengan memasuki pendidikan agama. Untuk tujuan ini Abu Qasim belajar kepada seorang ulama terkenal dari Sumatera Barat yang bernama Haji Muhammad Saleh. ${ }^{10}$ Setelah mengikuti pendidikan beberapa tahun, Abu Qasim melanjutkan pelajaran kepada guru lainnya di Tembusai, yaitu Maulana Syaikh Haji Abdul Halim saudara dari yang Dipertuan Besar Sultan Abdul Wahid Tembusai dan Syaikh Muhammad Saleh Tembusai, dua ulama tersohor di negeri Tembusai, Rokan, Riau. Abu Qasim menghabiskan lebih kurang tiga tahun untuk mendalami, ilmu nahwu, sharaf, mantik, tauhid, tafsir, hadis. Di antara buku yang dibacanya adalah kitab Fath al-Qarîb, Minhâj al-Thalibîn, Iqna', dan Tafsîr al-Jalalain. ${ }^{11}$ Kedalaman ilmunya dalam bidang fiqih menyebabkan beliau diberi gelar "faqih", dan karena itu, panggilannya berubah menjadi Fakih Muhammad. ${ }^{12}$

Perolehan gelar ini tidak membuat Abu Qasim puas. Dengan bantuan ayah angkatnya, Haji Bahauddin, Abu Qasim berangkat ke Makkah. Di kota suci Makkah Fakih Muhammad meneruskan studinya dan berguru kepada beberapa ulama kenamaan, seperti Syaikh Muhammad Yûnus bin 'Abd al- Rahmân Batubara, Syaikh Zain al-Dîn Rahwa dan Rukn al-Dîn Rahwa-yang berasal dari Indonesia-, Syaikh Muhammad Hasbullâh, Syaikh Zaini Dahlan-mufti mazhab Syafi'i.

Setelah menyelesaikan studinya di Makkah, beliau kembali ke kampung halamannya di Kubu, Tembusai, Riau. Di sana ia mulai menyampaikan dakwah dengan mengajarkan tauhid, fiqih dan ajaran tarekat Naqsyabandiyah. Untuk pusat kegiatan dakwahnya beliau membangun sebuah perkampungan yang disebut Kampung Mesjid. Kampung ini menjadi basis penyebaran agama Islam. Dari hasil dakwahnya ini, beberapa raja Melayu di pesisir Pantai Timur Sumatera Utara seperti Panai, Kualuh, Bilah, Asahan, Kota Pinang, Deli dan Langkat selalu mengundang Syaikh Abdul Wahab Rokan untuk berceramah di lingkungan dan kalangan istana. Sultan Musa Mu’azzamsyah dari Kesultanan Langkat menjadi pengikut tarekat Naqsyabandiyah yang setia sehingga ia diangkat menjadi khalifah.

Kendati Syaikh Abdul Wahab Rokan mendalami tarekat, namun Ia hidup secara

\footnotetext{
${ }^{10}$ Seorang ulama terkenal asal Minangkabau ahli dalam seni baca al-Qur'an (qari'). Sampai akhir hayat beliau mengajar al-Qur'an dengan tekun, meninggalkan ribuan murid, termasuk Abu Qasim. Karena kewarakannya sampai wafat ulama ini tidak berumah tangga, karena menurutnya, sulit mencari isteri yang benar-benar sebagai wanita saleh. Hal ini diilustrasikan seperti mencari seekor burung gagak putih di tengah-tengah kumpulan gagak hitam. Karena itu, banyak sekali suami masuk neraka karena isteri. Ibid., h. 20.

11 Ibid., h. 24.

${ }^{12}$ Pemberian gelar ini dilakukan melalui acara resmi, di hadapan suatu majelis, yang dihadiri khalayak ramai. Fakih berarti orang yang ahli dalam hukum fiqih atau sarjana hukum Islam. Gurunya melantik dengan ucapan: "Ikhwanul Muslimin, Abu Qasim bin Abdul Manap Tanah Putih, mulai sekarang ini alhamdulillâh di dalam penglihatan gurunya, dialihkan namanya dan dikurniai gelar dengan nama Tuan Fakih Muhammad bin Abdul Manap Tanah Putih berkat alFatihah". Ibid., h. 24-25.
} 
wajar, beliau juga berumah tangga dan memiliki keturunan. Bahkan Syaikh Abdul Wahab Rokan memiliki lebih dari satu orang istri. Ketika wafat pada tahun 1926, beliau didampingi oleh seorang istrinya yang bernama Siti yang berasal dari Batu Pahat, Malaysia.

Kehadirannya sebagai ulama yang disegani dan yang selalu mendapat dukungan dari raja-raja Melayu, membuat Belanda mencurigai gerak-gerik Syaikh Abdul Wahab Rokan yang mengakibatkan ia tidak merasa nyaman lagi tinggal di daerah Rantau Binuang, akhirnya ia pun pindah ke Kualuh (Labuhan Batu) atas permintaan Sultan Ishak penguasa Kerajaan Kualuh, di sana ia membuka perkampungan sebagai pusat dakwahnya yang namanya sama dengan perkampungan di Kubu yaitu Kampung Mesjid.

Setelah Sultan Ishak wafat, posisinya digantikan adiknya yang bernama Tuanku Uda, tetapi sangat disayangkan, Tuanku Uda kurang simpati kepada Syaikh Abdul Wahab Rokan. Sementara itu, Sultan Musa penguasa Kerajaan Langkat justru sangat mengharapkan agar Syaikh Abdul Wahab Rokan pindah ke Langkat. Setelah bermusyawarah dengan para muridnya, ia memutuskan untuk pindah ke Langkat, meninggalkan Kualuh. Di Langkat, tepatnya tahun $1300 / 1882$, ia mulai membangun perkampungan dan pusat persulukan tarekat Naqsyabandiyah yang bernama Babussalam.

Sesuai dengan sunnatullah, ada masa muda, tua dan akhirnya meninggalkan dunia yang fana. Tiga tahun setelah menerima bintang kehormatan, pada tanggal 21 Jumadil Awal 1345/ 27 Desember 1926, semua perjuangan berakhir, dan Syaikh Abdul Wahab Rokan wafat dalam usia 115 tahun. ${ }^{13}$

\section{Ajaran Syaikh Abdul Wahab Rokan}

Para pengikut tarekat Naqsyabandiyah Syaikh Abdul Wahab Rokan Babussalam berpegang kepada ajaran Tuan Guru Syaikh Abdul Wahab Rokan yang berasal dari pemikirannya yang tertuang dalam wasiatnya sebanyak 44 butir. ${ }^{14}$

\section{Hidup Hemat dan Sederhana}

Salah satu ajaran tarekat yang menjadi pegangan para pengikutnya adalah zuhud (zuhd) yaitu hidup hemat dan sederhana. Syaikh Abdul Wahab Rokan selelu mendorong para pengikutnya dan membuktikan bahwa hidup zuhud adalah suatu perjalanan spiritual menuju Allah. Hidup zuhud bukan berarti menafikan harta dan kehidupan dunia. Ia melihat harta kekayaan adalah nikmat dan anugerah Allah yang pantas diterima dan disyukuri. Namun walau memiliki harta, tidak harus digunakan secara berlebihan tetapi

${ }^{13}$ Fuad Said, Syekh Abdul Wahab, h. 149.

${ }^{14}$ Sejauh pelacakan penulis, asli tulisan wasiat ini tidak ditemukan lagi, namun isinya tidak berubah. Wawancara dengan H.A. Fuad Said tanggal 5 Agustus 2001. 
dimanfaatkan untuk membantu orang-orang yang lemah dan serba kekurangan. Ajaran ini dapat dilihat dari wasiatnya yang ke-3 yakni:

Di dalam mencari nafkah itu maka hendaklah bersedekah tiap-tiap hari... dan jika dapat ringgit sepuluh maka hendaklah sedekahkan satu dan taruh sembilan. Dan jika dapat dua puluh, sedekahkan dua dan jika dapat seratus, sedekahkan sepuluh dan taruh sembilan puluh. ${ }^{15}$

\section{Tegas dalam Pendirian}

Syaikh Abdul Wahab Rokan dikenal sangat warak. Ia sangat teguh dalam pendirian. Ia tegas terhadap maksiat, seperti memberantas perjudian, penyabung ayam dan minuman keras. Dalam hal pergaulan ia bisa berbaur dengan masyarakat bawah, tetapi juga dapat bergaul dengan para penguasa atau lapisan masyarakat elit, dengan tujuan untuk menyampaikan ajaran Islam umumnya dan tarekat khususnya.

Ajaran ini dapat dilihat pada wasiatnya yang ke-35 dan 36 berikut:

Jangan diberi hati kamu mencintai akan maksiat, artinya membuat kejahatan, karena yang demikian itu percintaan hati. Dan jika banyak percintaan hati membawa kepada kurus badan (35). Jangan kamu jabatkan tangan kamu kepada apa-apa yang haram, karena yang demikian itu mendatangkan bala (36). ${ }^{16}$

\section{Saling Tolong-Menolong}

Syaikh Abdul Wahab Rokan yakin bahwa seseorang tidak akan hidup tentram kalau hanya mementingkan diri sendiri. Hidup ini perlu saling tolong menolong karena sebenarnya manusia fakir ( $f a q r$ ) tidak memiliki sesuatu apapun di dunia ini. Makna fakir ialah apapun yang dimiliki baik harta, kekuasaan dan lain-lain, semuanya itu adalah milik Allah. Oleh sebab itu si kaya perlu membantu dengan hartanya, penguasa menolong dengan kekuasaannya dan yang lemah memberi bantuan dengan doanya. Semua lapisan saling bermanfaat dan tidak ada sia-sia. Ajaran ini dapat dilihat pada wasiat ke-10 dan 41 berikut ini:

Hendaklah kamu kuat menolong orang yang kesepian sehabis-habis ikhtiar sama ada tolong itu dengan harta benda atau tulang gega atau bicara atau doa. Dan lagi apa-apa hajat orang yang dikabarkannya kepada kamu serta dia minta tolong, maka hendaklah sampaikan seboleh-bolehnya (10). Apabila bertambah-tambah harta benda kamu dan bertambah-tambah derajat kamu, tetapi amal ibadat kamu kurang, maka jangan sekali-kali kamu suka akan yang demikian itu, karena yang demikian itu kehendak setan dan iblis dan lagi faedah harta bertambah-tambah dan umur berkurangkurang (41). ${ }^{17}$

\footnotetext{
${ }^{15}$ Fuad Said, Hakikat Tarekat, h. 168.

${ }^{16}$ Ibid, h. 173.

${ }^{17}$ Ibid, h. 169 dan 173.
} 
Dari wasiat yang tertera di atas dapat dipahami bahwa harta dan kekuasaan tidak ada manfaatnya kalau keduanya tidak digunakan untuk menolong sesama orang yang membutuhkan.

\section{Hidup Toleransi}

Ajaran tarekat adalah ajaran damai, jauh dari sifat kekerasan. Ajaran saling mengasihi, tidak saling menyakiti kepada sesama manusia, dan makhluk lainnya. Nabi Muhammad SAW. menjelaskan bahwa wanita yang mengikat kucingnya dan kemudian tidak memberi makan binatang itu akan masuk neraka kelak di akhirat. Sebaliknya, wanita jahat yang memberi minum kepada anjing yang akan mati karena kehausan diampuni dosanya oleh Allah. ${ }^{18}$

Contoh di atas menggambarkan bahwa sikap toleransi harus diberikan kepada sesama, walaupun dengan orang yang tidak seagama (kafir) selama mereka tidak menggangu. Tetapi bagi orang kafir yang menggangu harus dihadapi dengan tegas tanpa ragu-ragu. Ajaran ini dapat dilihat pada wasiat ke-9 dan 34 yang berbunyi:

Jangan kamu menghinakan diri kepada orang kafir laknatullah serta makan gaji dengan mereka itu. Dan jangan bersahabat dengan mereka itu melainkan sebab uzur syara' (9). Hendaklah berkasi-kasihan dengan orang sekampung dan jika kafir sekalipun dan jangan berbantah-bantah dan berkelahi dengan mereka itu (34). ${ }^{19}$

Dari ajaran ini dapat dilihat bahwa tidak ada toleransi terhadap yang batil dan memusuhi Islam, awalaupun beliau tetap mempersilahkan pengikutnya untuk menjalin persahabatan dengan orang yang tidak seagama dengan tidak meninggalkan etika pergaulan yang telah digariskan agama Islam.

\section{Etos Kerja}

Ada asumsi bahwa para pengikut tarekat tidak memerlukan harta benda dalam kehidupan di dunia ini. Sebab itu para pengikut tarekat dianggap tidak memiliki etos kerja karena hanya berzikir, suluk dan berdoa. Pandangan ini bertolak belakang dengan apa yang dilakukan Syaikh Abdul Wahab Rokan, yang bekerja keras membuka hutan belantara menjadi perkampungan dan membangun pertanian yang cukup baik.

Karenanya, Syaikh Abdul Wahab Rokan telah mendorong para pengikutnya untuk bekerja keras seperti wasiat yang ke-3, yakni: “...jika hendak mencari nafkah hendaklah

${ }^{18}$ Harun Nasution, Islam Rasional: Gagasan dan Pemikiran, cet. 4 (Bandung: Mizan, 1996), h. 212.

${ }^{19}$ Fuad Said, Hakikat Tarekat, h.169 dan 172. 
dengan jalan tulang gegah (dengan tenaga sendiri) seperti berhuma dan berladang dan menjadi amil." 20

Syaikh Abdul Wahab Rokan telah membuktikan bahwa dengan kerja kerasnya ternyata telah berhasil mengembangkan perekonomian masyarakat Babussalam sekaligus menjadi contoh kepada para pengikutnya.

\section{Rela Menerima Kenyataan}

Kewajiban manusia adalah bekerja dan berusaha. Bekerja dan berusaha itu juga bagian dari ibadah. Namun dalam bekerja sudah tentu harus mengikuti aturan-aturan agama, tidak berbuat merugikan orang lain. Jika hasil yang diperoleh tidak sesuai dengan apa yang diharapkan maka tidak boleh berputus asa, sebaliknya kalau mengalami keberhasilan tidak merasa sombong dan arogan serta menjauhi sifat ambisius. Rela menerima apa yang diberikan Allah (rida) adalah salah satu ajaran Syaikh Abdul Wahab Rokan yang tergambar dalam wasiat ke-6 dan ke-8 yang berbunyi:

Jangan kamu hendak kemegahan dunia dan kebesarannya, seperti hendak menjadi kadi dan imam dan lainnya, istimewa pula hendak menjadi penghulu-penghulu. Dan lagi jangan hendak menuntut harta benda banyak-banyak (6)... jangan dengki khianat kepada orang Islam. Dan jangan diambil harta mereka itu melainkan izin syara (8). ${ }^{21}$

\section{Mawas Diri}

Agar hidup ini selalu tentram dan damai harus dibarengi dengan upaya mendekatkan diri kepada Allah, merasa selalu diawasi-Nya akan terhindar dari perbuatan munkar dan akan menjadikan seseorang itu hidup jujur. Keyakinan seperti itu tertanam dalam Syaikh Abdul Wahab Rokan sebagaimana dalam wasiatnya ke-42 sebagai berikut:

Maka hendaklah kamu iktikadkan dengan hati kamu, bahwasanya Allah Ta'ala ada hampir kamu dengan tiada bercerai-cerai siang dan malam. Maka ia melihat apaapa pekerjaan kamu lahir dan batin. Maka janganlah kamu berbuat durhaka kepadaNya sedikit jua, karena Ia senantiasa melihat juga tetap hendaklah senantiasa kamu memohonkan keredaan-Nya lahir dan batin (42). ${ }^{22}$

Dari uraian di atas dapat dipahami bahwa Syaikh Abdul Wahab Rokan selain tetap mementingkan kehidupan spiritual seperti zikir, suluk dan tawajjuh, ia juga mendorong sifat mawas diri dalam menempuh kehidupan di dunia dan akhirat harus mendapat perhatian yang seimbang, sebagaimana tercantum dalam pendahuluan wasiatnya yang

\footnotetext{
${ }^{20} \mathrm{Ibid}, \mathrm{h} .168$.

${ }^{21}$ Ibid, h. 169.

22 Ibid., h.174.
} 
menegaskan bahwa martabat yang tinggi dan mulia hanya dapat dicapai bila ada keseimbangan kehidupan dunia dan akhirat tersebut.

\section{Amalan}

\section{Zikir}

Berzikir pada hakikatnya tidak hanya menyebut nama Allah, melainkan juga menghadirkan-Nya dalam hati. Karena itu berzikir dilakukan haruslah melalui tata cara yang digariskan oleh sang Syaikh tarekat. Khusus di suluk Babussalam, tata cara itu terdiri dari:

1. Menghimpun segala pengenalan dalam hati.

2. Menghadapkan diri ke hadirat Allah SWT.

3. Membaca istighfar sekurang-kurangnya tiga kali.

4. Menghadirkan roh Syaikh tarekat Naqsyabandiyah.

5. Menghadiahkan pahalanya kepada Syaikh tarekat Naqsyabandiyah.

6. Memandang Rabitah.

7. Mematikan diri sebelum mati.

8. Munajat dengan menyebut Ilâhi Anta Maqsûdî wa Ridhâka Mathlûbî. ${ }^{23}$

Adapun tata cara berzikir pada tarekat Naqsyabandiyah Babussalam lengkapnya adalah sebagai berikut:

Duduk dengan air sembahyang di atas tempat yang suci menghadap kiblat dengan duduk tawaruk sebelah kiri supaya hampir pandang kepada hati sanubari, maka hendaklah dipejamkan kedua mata dan dihimpunkan segala pengenalan di dalam hati sanubari, dihadapkan ingatan kepada ke hadirat Allah SWT. Tiada Seumpama-Nya, maka dibaca astaghfir allâh dua puluh lima kali dan diniatkan tubuh bersih dari pada segala maksiat lahir dan batin, besar dan kecil, kemudian maka dibaca fatihah satu kali, qul hua allâhu ậad tiga kali, dengan hadir hati itu kehadirat Allah SWT. dan demikian menghadiahkan pahalanya ke hadirat Syaikh Naqsyabandiyah serta diitikadkan hadirnya di hadapan kita minta tolong menyampaikan ma'rifat kita ke hadirat Allah SWT. Setelah itu hendaklah dipertemukan ujung lidah dengan langit-langit dan bibir di atas dengan bibir bawah, maka kita i'tikadkan diri kita sudah mati dan bahwasannya nafas kita ini ialah akhir nafas dan dimandikan, dikafankan, disembahyangkan serta ditanamkan ke dalam kubur hingga sampai hari kiamat dan huru hara di Padang Mahsyar dan dii'tikadkan bahwasanya tiadalah siapa-siapa yang boleh syafaat akan kita ke hadirat Allah Ta'ala, hanyalah guru kita tempat kita yang menerima tarekat ini kepada kita yaitu rabitah. Maka kita hadirkan rupa guru itu yaitu kita seperti kelakuan sewaktu dianya tawajjuh kepada kita maka apabila hadir ia telah nyata, kita pandang dengan hati sanubari kita itu maka bahwasanya yang demikian itu

${ }^{23}$ Ibid., h. 62. 
dinamakan rabitah yang boleh menolakkan was-was yang datang kiri dan kanan. Kemudian kita hadapakan ingatan dan pengenalan kita ke hadirat zat Allah yang Maha suci dari pada seumpamanya dan bandingan dan kita kata di dalam hati sanubari kita itu yaitu munajat tiga kali...Ilâhi Anta Maqshûdî ...tiga kali (hai Tuhanku Engkau jualah maksudku dan keridaan Engkau jualah yang aku tuntuti). Setelah itu kita katalah dengan hati sanubari itu zikir Allâh, Allâh, Allâh dengan bercepat-cepat serta diingat akan maknanya yaitu zat Allah Ta'ala serta kita bilang dengan tasbih apabila sampai seratus kali maka kita kata pula munajat itu kemudian maka kembali pula berzikir Allâh, Allâh, Allâh itu barang sekuasanya tetapi jangan kurang dari pada lima ribu dalam sehari semalam. Dan lagi hendaklah kita berzikir itu tetap sekalian anggota, sekalikali jangan bergerak-gerak dengan sekira-kira jika ada manusia hampiri kita itu niscaya tiada tahu halnya berzikir itu maka datang was-was dan bimbang kiri kanan maka hendaklah segera menghadirkan rupa rabitah. itu dalam hati sanubari dengan sempurna. ${ }^{24}$

\section{Rabitah}

Rabitah adalah menghadirkan rupa guru pada waktu hendak memulai zikir. Sesudah dalam keadaan zikir, tentu saja konsentrasi terpusat kepada Allah, dan di saat ingatan tertuju kepada Allah itu, tentu saja rupa Syaikh atau guru tidak terbayang lagi, apa lagi dalam keadaan fana' fí Allâh (hilang kesadaran), tenggelam dalam menyaksikan kebesaran Allah..$^{25}$

Hakikat rabitah pada ahli tarekat ialah bersahabat atau sebanyak mungkin beserta dengan mursyid (guru) yang pandai-pandai, yang hatinya selalu ingat kepada Allah. Melihat kepada orang-orang yang demikian atau kasih sayang kepada orang-orang itu, tidaklah dimaksudkan memperhambakan diri kepadanya atau memperserikatkan dia dengan Allah. ${ }^{26}$ Jadi rabitah itu adalah termasuk sifat kebiasaan manusia yang pasti ada pada dirinya. ${ }^{27}$

Rabitah yang artinya berkait atau bertali, dalam tarekat terbagi tiga : Pertama, rabitah wajib. Kedua, rabitah sunat. Ketiga, rabitah harus seperti melihat hal-hal baik ketika seseorang hendak mengikuti yang baik. ${ }^{28}$

Menghadirkan rabitah bagi pengikut tarekat, bertujuan supaya selalu ingat kepada Syaikh (mursyid). Dengan merasa selalu diawasi dan diperhatikan oleh Syaikh seorang pengikut tarekat akan merasa malu dan takut kalau melakukan sesuatu yang bersifat

${ }^{24}$ Yahya ibn Abdul Wahab Rokan, Adab Tharekat Naqsyabandiyah Babussalam (Buku tidak diterbitkan), h. 62-63.

${ }^{25}$ Abbas Husein Basri, al-Muzakkirah al-Zahabiyyah fì al-Tharîqah al-Naqsyabandiyah (t.tp: Aulad Toha al-Ghanimi, t.t.), h. 55. h. 332 .

${ }^{26}$ Abubakar Aceh, Pengantar Sejarah Sufi dan Tasawuf, cet. 8 (Solo: Ramadhani, 1994),

${ }^{27}$ Imron Abu Amar, Di Sekitar Masalah Tarekat Naqsyabandiyah (Kudus: Penerbit Menara, 1980), h. 56.

${ }^{28}$ Aceh, Pengantar Sejarah Sufi, h. 331. 
pelanggaran dari apa yang diajarkan Syaikhnya. Bimbingan yang diberikan Syaikh dalam amalan-amalan tarekat bukan dianggap sebagai suatu campur tangan, melainkan sebagai kawan dalam perjalanannya menuju ke sisi Tuhan. ${ }^{29}$

Rabitah merupakan pembimbing untuk mendekatkan diri kepada Allah, sebagaimana yang diungkapkan Kiai Bisri Mustafa sebagai berikut:

Allah Ta'ala Maha mengetahui dan Maha mendengar. Saudara jangan mengira bahwa tawassul kepada Allah Ta'ala dengan nabi-nabi atau wali-wali itu sama dengan memohon kenaikan tingkat kepada pihak atasan dengan perantaraan kepala kantor saudara. Pengertian tawassul yang demikian itu tidak benar. Sebab berarti mengalihkan pandangan terhadap yang dituju (pihak atasan), beralih kepada pihak perantara sehingga disamping mempunyai kepercayaan terhadap kekuasaan pihak atasan, saudara juga percaya kepada kekuasaan pihak perantara. Tawassul kepada Allah Ta'ala tidak demikian halnya. Kalau saudara ingin contoh tawassul kepada Allah Ta'ala dengan nabi-nabi atau wali-wali, coba saja perhatikan misal di bawah ini. Ada seorang majikan yang kaya raya dan memiliki perusahaan besar. Dia mempunyai beberapa orang pembantu yang paling dipercaya dalam mengendalikan perusahaannya. Saya ingin diterima menjadi pekerja dalam perusahaannya. Kebetulan saya kenal dengan salah seorang pembantu majikan tersebut untuk keperluan lamaran perkerjaan, saya diantar oleh pembantu majikan yang saya kenal tadi. Kepada majikan itu saya sampaikan maksud saya yaitu mohon diterima menjadi pegawai dalam perusahaannya, dan kenalan saya tersebut saya harapkan dapat membantu saya agar lamaran saya mendapat perhatian cukup dari sang majiakan. Coba pikirkan!

Kepada siapa sebenarnya saya mengajukan lamaran saya?. Kemudian apakah sia-sia saja saya diantar oleh teman saya tersebut sewaktu saya menghadap sang majikan? ${ }^{30}$

Dalam suluk Babussalam cara melaksanakan Rabitah adalah sebagai berikut:

1. Menghadirkannya di depan mata dengan sempurna.

2. Membayangkannya di kiri dan kanan, dengan memusatkan perhatian kepada rohaniahnya sampai terjadi sesuatu yang gaib. Apabila rohaniah mursyid yang dijadikan rabitah itu lenyap, maka murid tidak dapat menghadapi peristiwa yang terjadi. Tetapi jika peristiwa itu lenyap maka murid harus berhubungan kembali dengan rohaniah guru, sampai peristiwa yang dialami tadi atau peristiwa yang sama dengan itu muncul kembali. Demikianlah dilakukan murid berulangkali, sampai ia fana dan menyaksikan peristiwa gaib tanda kebesaran Allah. Rabitah menghubungkannya dengan Allah dan murid diasuh dan dibimbingnya terus menerus, meskipun jarak mereka jauh, seorang di barat dan seorang di timur.

3. Menghayalkan rupa guru di tengah-tengah dahi. Memandang rabitah di tengah-tengah

${ }^{29}$ Zamakhsyari Dhofier, Tradisi Pesantren: Studi Tentang Pandangan Hidup Kiyai (Jakarta: LP3ES, 1982), h. 138.

${ }^{30}$ Ibid. 
dahi itu, menurut kalangan tarekat lebih kuat dapat menolak getaran dan lintasan dalam hati yang melalaikan ingat kepada Allah.

4. Menghadirkan rupa guru di tengah-tengah hati.

5. Mengkhayalkan rupa guru di kening kemudian menurunkannya ketengah hati. Menghadirkan rupa Syaikh dalam bentuk keempat ini, agak sukar melakukannya, tetapi lebih berkesan dari cara-cara sebelumnya.

6. Menafikan dirinya dan menetapkan keberadaan guru. Cara ini lebih kuat untuk menangkis aneka ragam ujian dan gangguan-gangguan. ${ }^{31}$

\section{Perubahan di Babussalam}

\section{Bidang Sarana Fisik.}

Setelah Syaikh Abdul Wahab Rokan menetap di Langkat dan Sultan memberikan tanah seluas yang diperlukan, pada tahun 1300/ 1883 didirikan desa Babussalam, sebelah barat kota Tanjung Pura, di hulu sungai Batang Serangan.

Dalam perkembangan selanjutnya sebutan Babussalam lambat laun berubah menjadi Basilam, sebagai perkembangan pemudahan ucapan. Pada waktu itu Babussalam merupakan salah satu pusat utama tarekat Naqsyabandiyah Indonesia, dan barang kali yang terbesar. ${ }^{32}$

Syaikh Abdul Wahab Rokan bersama muridnya membuka perkampungan baru Babussalam dengan langkah awal yang dilakukan ialah mendirikan sebuah musala sederhana terbuat dari kayu yang berukuran 10 x 16 depa (lebih kurang 15 x 24 meter). Selain sebagai tempat salat, bangunan ini juga dijadikan sebagai tempat suluk, zikir, wirid dan pendidikan serta tempat bermusyawarah. Kemudian dalam perkembangan berikutnya, barulah dibangun rumah suluk untuk laki-laki dan wanita, rumah fakir miskin, dan tempat penampungan anak yatim.

Setelah perkembangan penduduk Babussalam demikian besar, musala yang lama tidak mampu lagi menampung jamaah. Pada tahun 1320/1902 Madrasah Besar didirikan oleh Syaikh Abdul Wahab Rokan sebagai pengganti musala yang dibangun pada tahun 1300/1882 yang berukuran kecil. Madrasah Besar yang baru ini berukuran 25x52 meter, terdiri dari tiga tingkat masing-masing tingkat mempunyai fungsi sendiri. Walaupun namanya madrasah tetapi memiliki fungsi sama dengan mesjid yaitu untuk tempat salat dan mengaji. ${ }^{33}$ Selain madrasah besar, dibangun pula rumah suluk yang memiliki peran penting dalam kegiatan persulukan. Rumah suluk tidak hanya berperan sebagai tempat tinggal atau tempat beristirahat para pengikut suluk, tetapi juga sebagai tempat di mana

${ }^{31}$ Fuad Said, Hakikat Tarekat, h. 71-72.

${ }^{32}$ Martin van Bruinessen, Tarekat Naqsyabandiyah di Indonesia, cet. 4 (Bandung : Mizan, 1996), h. 108.

${ }^{33}$ Fuad Said, Syekh Abdul Wahab, h. 75 
proses penyucian jiwa berlangsung. Di rumah suluk diadakan latihan dalam bentuk pelaksanaan zikir sesuai dengan ajaran yang dikembangkan. Karena itulah bangunan ini menjadi prioritas penting. Sejak awal berdirinya persulukan Babussalam terdapat dua bangunan rumah suluk, satu buah untuk laki-laki dan satu lainnya untuk wanita. Kegiatan suluk semasa Syaikh Abdul Wahab Rokan sampai sekarang selalu ada, kendati jumlahnya mengalami pasang surut.

\section{Bidang Kehidupan Sosial}

Perkampungan Babussalam diatur sedemikian rupa dengan struktur masyarakat dan tata aturan secara Islami, sehingga bisa disebut sebagai perkampungan Muslim. Di perkampungan ini selain ada musala seperti yang dijelaskan di atas, rumah penduduk diatur berjejer di depan dan di samping musala, sehingga setiap azan dapat didengar oleh seluruh penduduk yang ada di desa Babussalam. Pada saat ketika azan, muazin naik ke tempat yang tinggi dari musala, karena pada saat itu belum dikenal pengeras suara.

Sebagai daerah yang berstatus otonom, ${ }^{34}$ Babussalam diatur dalam PeraturanPeraturan Babussalam yang isinya antara lain:

1. Tidak boleh membiarkan ayam berkeliaran. Apabila ada ayam berkeliaran sanksinya dipandang sebagai milik bersama, sehingga boleh siapa saja menyembelihnya.

2. Tidak boleh merokok di depan umum.

3. Tidak boleh memakai peci hitam, harus memakai kopiah putih (lobe) atau memakai serban.

4. Tidak boleh berpangkas, tetapi harus bercukur (gundul).

5. Tidak boleh memakai perhiasan yang menyolok khusus bagi wanita.

6. Tiga kali berturut-turut tidak salat berjamaah akan dihukum. ${ }^{35}$

Bagi yang melanggar peraturan tersebut akan diberi sanksi yang dinamakan dam (hukuman) yaitu bertobat di halaman mesjid besar, selama beberapa jam dengan meneriakkan astaghfir allâh dan kalau menurut pertimbangan Syaikh Abdul Wahab Rokan kesalahan itu berat, maka beliau mengusir orang tersebut dari Babussalam. ${ }^{36}$

\section{Bidang Ekonomi}

Untuk memajukan kehidupan rakyat Syaikh Abdul Wahab Rokan mengembangkan

${ }^{34}$ Babussalam berhak membuat peraturan-peraturan tersendiri pada saat pemerintahan Kolonial Belanda sedang berkuasa. Bahkan Babussalam sendiri pada waktu itu telah mempunyai lambang atau bendera berwarna merah hijau. Ibid., h. 15 dan 75. Menurut Kepala Desa Babussalam sampai sekarang (2001) daerah persulukan Babussalam tidak dikenakan Pajak Bumi dan Bangunan (PBB) oleh pemerintah. Wawancara dengan Kepala Desa M. Affan Harahap, tanggal 28 Juli 2001.

${ }^{35}$ Fuad Said, Syekh Abdul Wahab, h. 74.

${ }^{36}$ Menurut Khalifah Abdul Madjid (76 tahun) penjaga makam tuan guru, hukuman pernah dilaksanakan, walaupun beliau tidak tahu persis berapa kali hukuman itu pernah dilaksanakan. Wawancara pada tanggal 28 Juli 2001 di Babussalam. 
usaha perekonomian dengan membangun perkebunan, peternakan, perikanan, dan percetakan.

Dalam bidang perkebunan Syaikh Abdul Wahab Rokan membuka perkebunan jeruk manis, perkebunan karet dan perkebunan lada. Di bidang peternakan, beliau membuka pertambakan ikan (tambak ini sampai sekarang masih ada walaupun sudah kurang terurus), peternakan ayam, kambing dan lembu.

Pada tahun 1326/1908 Tuan Guru membeli mesin cetak huruf Arab untuk mencetak kitab-kitab, dengan harga Rp 2500,-. Mesin cetak ini merupakan leter Arab yang pertama di Langkat, dan dapat mempekerjakan puluhan pekerja yang diambil dari penduduk Basilam. Kitab-kitab yang pernah dicetak dipercetakan ini antara lain:

1. Aqî̀ al-Imân, sebanyak 1000 eksemplar

2. Sifat dua puluh, sebanyak 1000 eksemplar

3. Nasihat Tuan Guru, sebanyak1000 eksemplar

4. Syair Nashîhat al-Dîn, sebanyak1000 eksemplar

5. Permulaan Dunia dan Bumi, sebanyak 500 eksemplar

6. Dalilyang cukup, sebanyak 500 eksemplar. ${ }^{37}$

Kecuali mencetak kitab-kitab yang disebut di atas, percetakan ini juga menerbitkan brosur dan siaran lainnya sebagai sarana dakwah. Dengan adanya percetakan ini nama Babussalam semakin tersiar ke seluruh penjuru. Hubungan persahabatan dengan para pemimpin Islam di berbagai negara bertambah erat. ${ }^{38}$

Pandangan Syaikh Abdul Wahab Rokan tentang ekonomi dapat dilihat dalam wasiatnya yang ketiga, di mana dalam wasiat itu ditegaskan bahwa dalam berniaga sangat diperlukan berserikat dan menabung yang sekarang dapat diartikan seperti koperasi. Wasiat itu adalah sebagai berikut:

Jangan kamu berniaga sendiri, tetapi hendaklah berserikat. Dan jika hendak mencari nafkah, hendaklah dengan jalan gega (tenaga sendiri) seperti berhuma dan berladang dan menjadi amil. Dan dalam mencari nafkah itu maka hendaklah bersedekah pada tiap-tiap hari supaya segera dapat nafkah. Dan jika dapat ringgit sepuluh maka hendaklah sedekahkan satu dan taruh sembilan. Dan jika dapat dua puluh sedekahkan dua. Dan jika dapat seratus, sedekahkan sepuluh, dan taruh sembilan puluh. Dan apabila cukup nafkah kira-kira setahun, maka hendaklah berhenti mencari itu dan duduk beramal ibadat hingga tinggal nafkah kira-kira empat puluh hari, maka barulah mencari. ${ }^{39}$

\section{Bidang Politik}

Sebagaimana dijelaskan Bruinessen bahwa para Syaikh Naqsyabandiyah umumnya

${ }^{37}$ Ibid. Sepanjang pelacakan penulis kitab-kitab hasil cetakan ini tidak ada ditemukan lagi sekarang.

${ }^{38} \mathrm{Ibid}$.

${ }^{39} \mathrm{Ibid}$, h. 168. 
cenderung mendekati penguasa dan mencari pengikut di kalangan elite politik. ${ }^{40}$ Keterlibatan para tokoh tarekat dalam politik yang dilakukan ialah untuk mendukung suatu sistem politik yang ada. Dalam kasus Babussalam, Syaikh Abdul Wahab Rokan mendukung Kesultanan Langkat. Dengan paradigma ini, kerjasama tokoh tarekat dengan penguasa merupakan sesuatu yang tidak terelakkan. Apa yang diperankan oleh Syaikh Abdul Wahab Rokan yang bekerjasama dengan Sultan Langkat adalah data sejarah bahwa adanya keterlibatan dalam politik.

Dalam dunia pergerakan kemerdekaan Indonesia, Syaikh Abdul Wahab Rokan ikut memainkan peranan penting. Pada tahun 1332/1913 ia mengirim delegasi ke musyawarah nasional Syarekat Islam (SI) di Jawa. Anggota delegasi adalah dua orang putra Tuan Guru, Pakih Tuah dan Pakih Tambah dan seorang tokoh bernama H. Idris Kelantan, mereka langsung bertemu dengan H.O.S. Cokroaminoto dan Raden Gunawan. ${ }^{41}$

Setelah delegasi ini kembali dari Jawa kepada mereka diberikan wewenang untuk mendirikan Syarikat Islam cabang Babussalam, yang diketuai oleh H. Idris Kelantan, sekretaris Hasan Tonel sedang Syaikh Abdul Wahab Rokan sebagai penasehat. ${ }^{42}$ Pendirian Syarikat Islam di Babussalam tidak terlepas dari strategi Tuan Guru sebagai suatu bentuk perlawanan terhadap kolonial Belanda.

Dengan demikian Syaikh Abdul Wahab Rokan seorang yang cerdas dalam berpolitk pada zamannya. Menurut teori Alex Inkles salah satu ciri manusia modern adalah aktif berpolitik. ${ }^{43}$ Dari ciri-ciri manusia modern tersebut Syaikh Abdul Wahab Rokan dapat dikategorikan sebagai manusia modern pada zamannya dan dengan posisinya itulah nampaknya tarekat Naqsyabadiyah Babussalam dapat bertahan sampai kini dan dapat menyebar bukan saja didalam negeri tetapi juga ke mancanegara.

\section{Bidang Pendidikan dan Pengkaderan}

Hampir pada setiap tempat yang dikunjunginya, Syaikh Abdul Wahab Rokan selalu mengangkat khalifah. Sepanjang hidupnya, ia telah mengangkat sebanyak 126 khalifah, tersebar di daerah Langkat, Deli Serdang, Asahan, Panai, Kota Pinang, Tapanuli Selatan, yang semunya berada di Sumatera Utara. Di Riau, terdapat di daerah Kubu, Tembusai, Tanah Putih, Rambah, Indragiri, Rawa, Kampar dan Siak. Juga terdapat di Sumatera Barat, Aceh dan Jawa Barat. Sementara di mancanegara terdapat di Malaysia seperti di Batu Pahat, Kelantan, Kelang, Selangor dan Perak. Sementara itu ada juga khalifah yang berasal dari Cina. ${ }^{44}$

${ }^{40}$ Martin van Bruinessen, Kitab Kuning, Pesantren dan Tarekat, cet. 3 (Bandung: Mizan, 1995), h. 334.

${ }^{41}$ Fuad Said, Syekh Abdul Wahab, h. 119-120.

${ }^{42}$ Ibid.

${ }^{43}$ Jalaluddin Rahmat, Rekayasa Sosial (Bandung : Remaja Rosdakarya, 2000), h. 169.

${ }^{44}$ Fuad Said, Syekh Abdul Wahab, h. 141-144. 
Di samping mengangkat khalifah, masih ada murid yang khusus datang menuntut ilmu ke Babussalam. Mereka berasal dari Sumatera Utara, Tapanuli, Aceh, Jawa, Bugis, Bangka dan Bengkalis. Dari mancanegara berasal dari Malaysia seperti daerah Perak, Perlis, Trenggano, Kelang, Malaka, Pahang, Pulau Pinang, Kedah dan Kelantan. Ada juga murid yang berasal dari India, Siam, Singapura dan Patani. ${ }^{45}$ Karenanya, Babussalam menjadi pusat tarekat terbesar di Nusantara.

Secara teratur, para pengikut tarekat mengadakan pertemuan-pertemuan dalam rangka melaksanakan zikir bersama atau mengadakan suluk/khalwat selama sepuluh, duapuluh, bahkan bisa empat puluh hari. Hubungan tradisi yang emosional ini merupakan suatu ikatan yang kuat di kalangan sesama pengikut tarekat.

Tidak semua khalifah yang diangkat oleh Syaikh Abdul Wahab Rokan memiliki persulukkan tetapi hanya sebagian saja yang membukanya di daerah masing-masing. Di Indonesia, dapat ditemukan di Padangsidempuan, pimpinan Khalifah Abdul Manan, di Labuhan Bilik (Panai) dipimpin Khalifah Junid, di Air Bangis (Sumatera Barat) dipimpin Khalifah Hasan, di Gunung Selamat (Labuhan Batu) dipimpin Khalifah AM Thaib, sementara di Kerinci (Jambi) dipimpin oleh Khalifah Ramadhan, di Rokan (Riau) dipimpin oleh Khalifah M. Saleh, di Alas (Aceh Selatan) dipimpin oleh Khalifah Panjang. ${ }^{46}$

Perkembangan tarekat Naqsyabandiyah Syaikh Abdul Wahab Rokan juga terjadi di Malaysia. Di sana dapat dijumpai beberapa tarekat yang berafiliasi dengan tarekat Naqsyabandiyah Babussalam, semisal di Batu Pahat (Johor), dipimpin Khalifah Usman, di Perlis dipimpin Khalifah Hasan, setelah ia wafat diganti Khalifah Dawi, di Temong (Perak), dipimpin Khalifah Muhammad Yatim, sementara di Pahang dipimpin Khalifah Umar, yang kemudian digantikan Khalifah Imam Ishaq dan di Kuala Lukut (Negeri Sembilan), dipimpin Khalifah Tambi. Salah satu tarekat Naqsabandiyah yang terbesar di Malaysia terdapat di Kajang (Selangor), dipimpin oleh Khalifah Yahya bin Laksamana. Persulukan ini berada lebih kurang delapan kilometer dari kota Kajang, terletak di balik perkebunan kelapa sawit. Di sana, terdapat bangunan mesjid besar, sebuah asrama, rumah suluk dan rumah para pengikut Syaikh Yahya. ${ }^{47}$

\section{Membina Persaudaraan}

Tidak jarang sebagai sesama ikhwân yang mempunyai hubungan emosional, para khalifah ini mengadakan pertemuan-pertemuan zikir dan tawajjuh. Pertemuan-pertemuan ini (zikir dan tawajjuh) selain berfungsi melestarikan ajaran Tuan Guru, juga sebagai perekat jaringan di kalangan para khalifah dan pengikut tarekat yang bisa menjadi perkumpulan

${ }^{45}$ Ibid., h. 147.

${ }^{46}$ Bruinessen, Tarekat Naqsyabandiyah, h. 137-138. Lihat juga Fuad Said, Syekh Abdul Wahab, h. 147.

${ }^{47}$ Bruinessen, Tarekat Naqsyabandiyah, h. 161 
kooperatif. Suatu jaringan yang rapi terdiri dari Syaikh, khalifah, dan anggota tarekat yang dalam hal ini menunjukkan bahwa tarekat bisa menjadi organisasi sosial dan mempunyai potensi politik.

Setelah wafatnya Syaikh Abdul Wahab Rokan, bentuk jaringan ini semakin kuat dan nyata melalui peran khalifah, upacara yang disebut hul berlangsung meriah setiap tahunnya dalam rangka memperingati hari wafatnya Tuan Guru. Pada acara hul ini hadir para Syaikh, khalifah, pengikut dan simpatisan tarekat Naqsyabandiyah Babussalam, baik yang berasal dari tanah air maupun mancanegara dan diperkirakan mencapai puluhan ribu orang. Peringatan hul ini diisi dengan membaca kembali riwayat hidup dan perjuangan Syeh Abdul Wahab Rokan, berzikir, tawajjuh, dan ceramah agama, yang sebelumnya didahului dengan melakukan suluk selama empat puluh hari.

Dengan demikian, ciri tradisional tarekat terbukti mampu membentuk rasa solidaritas sosial dan sebagai jaringan pemersatu masyarakat tarekat. Dalam pertemuan hul ini terjadi proses saling tukar informasi. Mereka bukanlah kelompok marjinal, eksklusif atau terasing dari masyarakatnya, bahkan sebagian mereka adalah tokoh-tokoh masyarakat yang berperan sebagai aktor dalam proses perubahan karena keterlibatan dalam kehidupan sosial menjadi keniscayaan bagi mereka.

\section{Bidang Dakwah}

Tidak terlalu berlebihan kalau disebutkan Syaikh adalah pemimpin spritual, menduduki posisi elit dalam tarekat, dan selalu mendapat kesetian dari berbagai lapisan pengikutnya. Kesetiaan yang menuntut penyerahan total tersebut merupakan tradisi yang dituntut dari setiap murid. Apapun keputusan Syaikh, selalu diterima murid sebagai sesuatu yang sakral, karena adanya keyakinan bahwa Syaikh selalu memperoleh petunjuk dan barakah dari Allah.

Syaikh Abdul Wahab Rokan sebagai figur dan tokoh tarekat yang dihormati di Kerajaan Langkat memanfaatkan posisi berharga itu untuk menjalankan misi dakwahnya. Ia memakai strategi dengan menjalin hubungan baik dengan sejumlah raja-raja Melayu, seperti penguasa Kerajaan Bilah, Panai, Kota Pinang, Asahan, Deli dan Langkat, semuanya terletak di pesisir Timur Sumatera Utara. Bahkan, Sultan Musa Mu'azzamsyah dari Kerajaan Langkat dikenal sebagai murid Syaikh Abdul Wahab Rokan dan sultan diangkatnya sebagai khalifah. Di kerajaan-kerajaan ini ajaran syariat dan tarekat benar-benar diamalkan, dan hingga saat ini pun tarekat Naqsyabandiyah di pesisir Timur Sumatera Utara, Riau dan sebagian Malaysia masih berafiliasi ke Babussalam.

Di samping hubungan baik dengan penguasa, Syaikh Abdul Wahab Rokan menyampaikan dakwah Islam dengan pendekatan hubungan tali kekeluargaan. Untuk itu, ia menikah hampir di setiap tempat yang dikunjunginya, tentu saja dalam melakukan penikahan tersebut selalu mematuhi hukum syariat. Dengan banyak dan tersebarnya 
keluarga sudah barang tentu akan memberikan kemudahan kepadanya dalam menyampaikan dakwah terutama mengembangkan ilmu tarekat.

Masih dalam rangka pengembangan dakwah, Syaikh Abdul Wahab Rokan membangun sebuah percetakan yang menerbitkan brosur-brosur dakwah dan buku-buku agama tidak kurang dari delapan ribu eksemplar, dengan sepuluh judul, suatu jumlah yang cukup besar saat itu. Dengan adanya percetakan ini nama Babussalam semakin lebih tersiar ke berbagai kerajaan. ${ }^{48}$

\section{Penutup}

Tarekat Naqsyabandiyah yang didirikan Syaikh Abdul Wahab Rokan satu abad yang lalu, sudah memperlihatkan kecenderungan bahwa berbagai lapisan sosial masyarakat telah menjadi pengikut tarekat ini. Karena mereka menginginkan dan menyadari bahwa kebutuhan lahir dan batin harus sejalan seimbang dan harmonis kalau ingin kehidupan ini dilalui dengan ketenangan. Kharisma Syaikh Abdul Wahab Rokan dengan keteguhan pendirian, satunya perkataan dengan perbuatan, dan menghadapi dunia secara realitas apa adanya. Dengan demikian menjadikan tarekat ini semakin dicintai dan beliau menjadi contoh teladan yang baik, walaupun beliau sudah tiada, tetapi keramatnya masih tetap diharapkan oleh para pengikutnya.

Akhirnya, sebagaimana telah terbukti di masa lalunya, tarekat Naqsyabandiyah Babussalam mampu memberi kontribusi yang sangat besar dan dalam bidang kehidupan, ke depan dapat diharapkan tarekat Naqsyabandiyah Babussalam akan tetap memainkan perannya yang sentral bagi kehidupan. Babussalam tetaplah akan menjadi mata air ketentraman batin bagi umat disekitarnya. Babussalam akan tetap menjadi panduan spiritual bagi umat yang akan terus semakin membutuhkannya.

\section{Pustaka Acuan}

Aceh, Abubakar. Pengantar Sejarah Sufi dan Tasawuf. Solo: Ramadhani, 1994.

Amar, Imron Abu. Di Sekitar Masalah Tarekat Naqsyabandiyah. Kudus: Penerbit Menara, 1980.

Armstrong, Amatullah. Sufi Terminology (al-Qamus al-Sufi; The Mistical Language of Islam, terj. M. S Nashrullah dan Ahmad Baiquni. Bandung: Mizan, 1998.

Basri, Abbas Husein. al-Muzakkirah al-Zahâbiyyah fĩ al-Tharîqah al-Naqsyabandiyah. t.tp: Aulad Toha al-Ghanimi, t.t.

Bruinessen, Martin van. Kitab Kuning, Pesantren dan Tarekat. Bandung: Mizan, 2001.

${ }^{48}$ Fuad Said, Syekh Abdul Wahab, h. 119 
Bruinessen, Martin van. Tarekat Naqsyabandiyah di Indonesia. Bandung: Mizan, 1996.

Departemen Agama Republik Indonesia. Al-Qur'an dan Terjemahannya. Jakarta: Proyek Pengadaan Kitab Suci Al-Qur'an, 1985.

Dhofier, Zamakhsyari. Tradisi Pesantren: Studi Tentang Pandangan Hidup Kiyai. Jakarta: LP3ES, 1982.

Al-Kasyyani, Abd al-Razzaq. Ishthilâhat al-Sufiyyah. Kairo : Dâr al-Ma'ârif, 1984.

Al-Kurdî, Muhammad Amîn. Taḩzî̉b al-Mawahib al-Sarmadiyyah fí Ajilla’i al-Sadah alNaqsyabandiyah. Damaskus: Dâr Hara', 1996.

Al-Kurdî, Muhammad Amîn. Tanwîr al-Qulûb fî̀ Mu'amalah 'Allam al-Ghuyub. t.tp: Dâr Ihyâ' al-Kutub al-'Arabiyyah, t.t.

Muhammad, A. Djalil dan H. Abdullah Syah. Sejarah Dakwah Islamiyah dan Perkembangannya di Sumatera Utara. Medan : MUI Sumatera Utara, 1983.

Nasution, Harun. Islam Rasional; Gagasan dan Pemikiran. Bandung: Mizan, 1996.

Rahmat, Jalaluddin. Rekayasa Sosial. Bandung: Remaja Rosdakarya, 2000.

Rokan, Yahya ibn Abdul Wahab. Adab Tarekat Naqsyabandiyah Babussalam. Tidak dipublikasikan.

Said, H.A. Fuad. Hakikat Tarekat Naqsyabandiyah. Jakarta: PT. al-Husna Zikra, 1999.

Said, H.A. Fuad. Syaikh Abdul Wahab, Tuan Guru Babussalam. Medan: Pustaka Babussalam, 1998.

Sinar, T. Luckman. "Kerajaan-Kerajaan Melayu” pada Dirasah al-'Ulya. Medan: MUI SU, 1999.

Suminto, Aqib. Politik Islam Hindia Belanda. Jakarta: LP3ES, 1985. 